\title{
COVID-19 and Dental Education in Pakistan
}

\author{
Muhammad Mansoor Majeed ${ }^{1}$, Muhammad Shoaib Durrani ${ }^{2}$, Muhammad Bilal Bashir $^{3}$ and Muhammad Ahmed ${ }^{4}$ \\ ${ }^{1}$ Department of Oral Biology, Altamash Institute of Dental Medicine, Karachi, Pakistan \\ ${ }^{2}$ Durrani Dental Clinic, Karachi, Pakistan \\ ${ }^{3}$ Department of Oral Biology, Dow University of Health Sciences, Karachi, Pakistan \\ ${ }^{4}$ Department of Oral \& Maxillofacial Surgery, Shaheed Zulfiqar Ali Bhutto Medical University, PIMS Hospital, Islamabad, Pakistan
}

\begin{abstract}
The spread of severe acute respiratory syndrome coronavirus 2 (SARS-CoV-2) has infected more than 6 million people globally; and changed the dynamics of the entire world. In March 2020, novel coronavirus disease 2019 (COVID-19) was declared as a pandemic by the World Health Organization (WHO). In Pakistan, the first case of COVID-19 was reported on 26 $6^{\text {th }}$ February, 2020. The virus is highly contagious and spreads mainly by aerosols. Its major symptoms include sore throat, cough, high-grade fever, anosmia, etc. Like other countries, it has also affected all fields of life in Pakistan, but its impact on dental education and dentistry has been particularly devastating. Dental institutes are at particularly high risk for infection transmission through their aerosol-generating dental procedures. In the scenario of a lockdown, dental students are suffering a lot and the dental colleges and faculties must try their best to overcome this situation. This article aims to review the challenges faced by dental community to carryout teaching and training in dental education during the COVID-19 pandemic.
\end{abstract}

Key Words: COVID-19, Dentistry, Education, Pakistan, Pandemic.

How to cite this article: Majeed MM, Durrani MS, Bashir MB, Ahmed M. COVID-19 and Dental Education in Pakistan. J Coll Physicians Surg Pak 2020; 30(JCPSPCR):CR115-CR117.

The newly discovered viral disease, known as novel coronavirus disease (COVID-19) has changed the world. First started in Wuhan in December 2019, it has spread to almost all countries of the world and infected more than 6 million individuals as of May, 2020. In Pakistan, the first case of the virus was reported on $26^{\text {th }}$ February, 2020 as a university student travelled from Iran, which was the epicenter of this virus after China. ${ }^{1}$ Due to rapid spread of pandemic of COVID-19, things are going haphazard in the entire world. The same is the case in Pakistan. All group-based activities have been severely put down to a grinding halt. This includes music concerts, dine-in restaurant businesses, huge malls, religious, educational and even group physical activities.

The virus is highly contagious and changing its nature quickly. It is suggested that the route of human-to-human transmission is by aerosols, airborne droplets, touching of infected surface, or coming in close contact with the infected individuals. In order to implement social distancing since March 2020, Government of Pakistan has suspended or closed all teaching institutes including schools, colleges, and universities as well as medical and dental colleges.

Correspondence to: Dr. Muhammad Mansoor Majeed, Department of Oral Biology, Altamash Institute of Dental Medicine, Karachi, Pakistan

E-mail: mmansoormajeed@gmail.com

Received: June 01, 2020; Revised: June 08, 2020;

Accepted: June 25, 2020

DOI: https://doi.org/10.29271/jcpsp.2020.JCPSPCR.CR115
Later on, a strict lockdown was imposed throughout the country that was not only limited to teaching but also on the out patient departments (OPDs) of the hospitals.

It is reported that dental healthcare professionals (DHCPs) along with dental nurses, hygienists, dentistry students, etc. are at increased risk of acquiring COVID-19 due to routine aerosol-generating procedures in and around the patient's mouth. ${ }^{2}$ Several dental colleges and teaching hospitals around the world have temporarily shut down due to the reported cases of cross-infection and they have stopped all undergraduate dentistry students and studentsin postgraduate programmesand working clinical attachments from their in-hospital teaching and training activities.

In Pakistan, the total number of dental colleges in all provinces are 55 (Table I). ${ }^{3}$ As per Pakistan Medical and Dental Council (PMDC), themaximum numberofdental studentsfrom $1^{\text {st }}$ to final yearBachelor of Dental Surgery (BDS) in all dental colleges of the country are about $12800 .{ }^{3}$ All of the dental colleges in Pakistan have also suspended teaching activities. Moreover, in the majority of dental colleges, clinical activities are only limited to emergencies with a restricted number of dentists and supporting staff. Currently, the biggest challenge for dental colleges is not only the health of the students and faculty but to ensure the continuity in the education of the future dentists.

Dental colleges are taking classes on online platforms. Few dental colleges are conducting live lectures on ZOOM, Google Classroom, etc. and some are sending the prerecorded videos along with the lecture presentation to students either on email or in social mediagroups. 
Table I: Number of recognised dental colleges in different provinces of Pakistan.

\begin{tabular}{|c|c|c|c|}
\hline Province & Public & Private & Total \\
\hline Balochistan & 01 & 06 & 01 \\
\hline K.P.K & 04 & 22 & 10 \\
\hline Punjab & 04 & 12 & 26 \\
\hline Sindh & 06 & 40 & 18 \\
\hline Total & 15 & 55 \\
\hline
\end{tabular}

In Pakistan, where high-speed internet facilities are limited to big cities, it is very challenging for those students who belong to remote areas. Moreover, in online classes, it is relatively difficult to question and manage time. Along with the technical difficulties, students are facing many more issues.

Basic science subjects could be taught online, to some extent; but, laboratory procedures, practical and pre-clinical procedures can neither be performed nor learned in this manner. For example, in the subject "oral biology" where students need to carve teeth, prepare slides and carry out other procedures; and in dental materials where plasterwork and manipulation of impression material are part of their curriculum. Likewise, in pre-clinical dentistry, where students are responsible for designing partial dentures and perform restorative procedures on the artificial teeth in the phantom head lab.

Additionally, education, training, and practical exposure to patients is another highlighted issue. A considerable number of dentistry students are in the process of preparing for or undertaking training that requires clinical exposure with patients. And this is the key component in the syllabus of BDS. Though in few dental colleges, faculties are trying their best to show procedures like teeth set-up for a complete and partial denture, wire bending, cavity design, etc. on online videos and using phantom heads or other simulation techniques; but it is evident that virtual sessions cannot match the up-close experience with patients. This scenario is particularly stressful to those dental students who are in their house job or in the third or final year, and are most likely to resume training soon or will start the practical life. Many dental clinics, where these students perform observership, have reduced the number of patients as well as staff that also includes dental interns, in order to prevent themselves and other individuals from acquiring and spreading the disease. Due to COVID-19, national and international hospitals have suspended, postponed, or cancelled elective procedures; and this would not only cause anxiety to students, but also lead to a missed opportunity of working in another hospital within or outside the country. Moreover, community trips, rotations to medicine, and surgery ward have also been cancelled. This will have a huge negative impact on the quality of young dental HCPs, who will enter real-life clinical situations without having adequate hands-on skills or training. This will play a major role in the decline of dental services being provided in government and private dental facilities.
There is a lot of panic everywhere and general ambiguity amongst dental surgeons and dental students about their studies, level of competence, capabilities, finances and professional future that is escalating day by day and currently, it is too early to predict what will happen as most of the dental schools follow official advisories issued by the respective health ministry. ${ }^{4,5}$

Online teaching is not only difficult for students but the teachers are also facing a lot of problems to adapt to the new mode of teaching. Most of the teaching faculty is not tech-friendly and without any training and prior experience regarding online classes; and it is similarly very difficult for them to follow this method. Repeated disconnections, unavailability of the board, non-serious students, and other unfortunate circumstances are the issues faced by the teachers.

This is the time for the dental faculty to learn how to teach online. Many online courses are available that will not only help the teaching faculty during this pandemic, but further improve their knowledge and skills. The success of elearning depends on the attitudes and interactive teaching styles of the faculty, as well as on the experience and attitudes of students concerning

technology. This will be a good opportunity for the higher management of dental colleges to invest in online training for the teaching staff. Moreover, the administration should consider organising psychological sessions for students, as they are in psychological stress. To reduce the anxiety, policies regarding attendance, grading, etc. should be modified as this pandemic has given a lot of psychological stress to the students. ${ }^{6}$ Dental colleges and higher authorities should focus on re-evaluating and reprioritising their policies and protocols and include a detailed contingency plan in case of future pandemics.

Recommendations, protocols, and guidelines have been issued by the Royal College of Dentistry, American Dental Association, Pakistan Dental Association, and other dental bodies in the interest of operators as well as for patients, to carry out dental procedures including emergency dental procedures. Moreover, during the current pandemic, multiple webinars have been conducted; and from these webinars, students as well as dentists, could gain knowledge and improve their skills. Moreover, Hazmat suits, FFP2/3 masks or respirators, proper ventilation in the dental operatory, and other protocols have to be considered.

But, in such difficult and challenging times, we should remember that we only lose when we give up; and we all are 
waiting to see what ingenuities for dental education will emerge in the face of the COVID-19 pandemic.

\section{CONFLICT OF INTEREST:}

The authors declared no conflict of interest.

\section{AUTHORS' CONTRIBUTION:}

MMM: Study concept and design, write-up, supervised the project and is responsible for the integrity of the research. Critically revised and approved the final draft of the manuscript.

MSD: Literature search, initial draft writing, critical revision of the manuscript and final approval.

MBB, MA: Literature search and contributed in writing of the manuscript and approved the final draft of the manuscript.

\section{REFERENCES}

1. Saqlain M, Munir MM, Ahmed A, Tahir AH, Kamran S. IS Pakistan prepared to tackle the coronavirus epidemic? Drugs Ther Perspect 2020; 36:213-4. doi: 10.1007/ s40267-020-00721-1.

2. Zemouri C, de Soet $H$, Crielaard W, Laheij A. A scoping review on bio-aerosols in healthcare and the dental environment. PLoS One 2017; 12(5). doi: 10.1371/ journal.pone. 0178007.

3. PMDC. Recognized dental colleges in pakistan 2020 [Available from: http://www.pmdc.org.pk/RECOGNIZED DENTALCOLLEGESINPAKISTAN/tabid/167/Default.aspx. [Accesed May 2020]

4. Iyer P, Aziz K, Ojcius DM. Impact of COVID-19 on dental education in the United States. J Dent Edu 2020; 84(6): 718-22. doi: 10.1002/jdd.12163.

5. Saleem Z, Majeed M, Rafique S, Siddiqui Z, Ghandhi D, Tariq $\mathrm{H}$, et al. COVID-19 pandemic fear and anxiety among healthcare professionals in Pakistan, 23 June 2020, PREPRINT (Version 1) available at Research Square [+http://doi.org/10.21203/rs.3.rs-37608/v1+]

6. Cao W, Fang Z, Hou G, Han M, Xu X, Dong J, et al. The psychological impact of the COVID-19 epidemic on college students in China. Psychiatry Res 2020; 112934. doi: 10.1016/j.psychres.2020.112934. 